\title{
Duplicate Exchange Union
}

The evolution of an enterprise looking to the enhancement of college library resources is described by the chairman of the committee recently in charge of it.

\section{$\mathrm{T}$} he Duplicate Exchange Union, sponsored by the Association of College and Reference Libraries, has been operating for nearly four years. It was organized in 1940 by Neil Van Deusen, then librarian of Fisk University in Nashville. Dr. Van Deusen had sensed the need for organizing the exchange of periodicals. The plan decided upon was for libraries to exchange periodicals on a piece-by-piece basis, with no definite effort being made to have each library give as much as it received, or vice versa.

Dr. Van Deusen, in considering the method to be followed, had to decide on a routing scheme. He devised a plan by which libraries would be listed in the order of their expenditures for periodicals. $\mathrm{He}$ approached scores of libraries and obtained an initial group to begin the project. The periodical expenditures reported were submitted to the American Library Association for certification. The routing sheet was compiled, listing the library with the largest periodical expenditures first and the others in order.

Copies of this list were sent to each member. In turn, each member was to attach a copy of its duplicate list to the routing sheet and send it to the first library on the list. After this library had requested what it needed, it then was to send the list and routing sheet to the next library, and so on down the routing sheet.

The following rules were adopted when the Periodical Exchange. Union first began to function in 1940:

I. Each participating library shall prepare a list of its duplicate periodical material. This list must include: the name of the library offering the material; its location; the name of the person to whom exchange requests should be addressed.

II. All participating libraries agree to the free exchange of all duplicate material listed.

III. Each library shall give volume, number, and date for all duplicates.

IV. Duplicate lists when prepared should be forwarded directly to the first library on the routing list.

V. When duplicate lists are received, prepare a list of wanted items and forward this list of wanted items to the library offering them.
a. Specify the transportation desired.
b. Acknowledge receipt of items.
c. Correct lists before forwarding to next library on routing list.
d. Runs of volumes may be broken, but in- dividual complete volumes may not be.
VI. Please do not keep any list over one
VII. Please keep a record of: week.

a. The number of pieces sent to libraries participating in the union:

I. Bound volumes.

2. Unbound complete volumes.

3. Separate numbers.

b. The number of pieces received from libraries participating in the union (same figures as under $a$ above).

c. The libraries from whom lists have been received and checked.

d. The libraries from whom material has been received. 
VIII. The last library on the list is expected to return all duplicate lists to the library owning the remainder of the duplicates.

After a year Dr. Van Deusen was forced to give up his active leadership of the Periodical Exchange Union. Mrs. Marjorie Keenleyside, librarian of the Central Y.M.C.A. College in Chicago, was asked to become temporary chairman. Mrs. Keenleyside carried on the work for about eight months. During this period some changes were made in the procedure. Complaints had been made that the routing sheets were being held too long by individual libraries. After consultation with some members and a meeting at the annual conference of the American Library Association in Milwaukee in June 1942, Mrs. Keenleyside decided to try an alternate plan. This plan consisted of having members send out lists simultaneously to all other members, allowing about a month for checking, and then filling requests in order of the routing sheets. Members could use either this new plan or the original plan.

In September 1942, the president of the Association of College and Reference Libraries appointed a committee of three, of which the writer is chairman, to handle the procedures of the Periodical Exchange Union. The two other members of the committee were Virginia Trumper, in charge of periodicals for the library of the Woman's College of the University of North Carolina, and Oscar C. Orman, librarian of Washington University in St. Louis. When Mr. Orman was called into the armed services he was replaced on the committee by Alice Palo, acquisition librarian of the University of Cincinnati.

When the committee took over the work there were several libraries waiting to join the union, making it necessary to compile a new routing sheet. The committee sent requests to all members asking for a new statement of periodical expenditures. At this time the same information was requested from prospective members. In February 1943 a revised routing sheet was completed.

During the first three years of the union's existence there were many differences of opinion as to the best methods of operation. Libraries at the head of the routing sheet were fairly well satisfied because they had the pick of titles offered on exchange lists. Libraries far down on the list complained that the "cream of the crop" was taken by the time their requests were made. Many members wrote to the chairman and offered suggestions. It became apparent that new changes were necessary.

The committee compiled a questionnaire that was sent to all of the members. An analysis of this questionnaire might be of interest. Fifty of the seventy members answered. The following is a summary of their answers.

I. Question: Do you feel that the union has been beneficial to your library?

Answer: Forty-six libraries indicated that the union had been beneficial. Some stated that they had received more than they had sent out. Others were glad for the opportunity to pass on their duplicates, regardless of how much material they had received. The answers of the other four members ranged from "not yet" to "doubtful."

2. Question: Should the number of members be limited? If so, approximately what number?

Answer: Twenty-eight libraries thought there should be no limit on membership. The remainder gave no answer or thought there should be some restrictions.

3. Question: Do you think there should be a division within the union, that is, type of library, etc.?

Answer: Thirty-seven members thought there should be no division by type of library. Some suggested a geographical or subject division.

4-5. Question: Have you any special types 
of material you would like to receive in preference to other types, such as government documents, books, etc.? Do you think the activities of the union should be expanded to include any types of material mentioned in number 4 ?

Answer: There was no decided opinion. Many libraries indicated that they would like to receive government documents and books but most stated that they were interested primarily in periodicals. Most libraries thought that all types of material should be included.

6. Question: What do you think about sending out want lists regularly or occasionally?

Answer: There was no decided opinion regarding this question. Some libraries indicated that they did not have time to send out want lists in addition to regular exchange lists.

7. Question: Are you satisfied with the present methods of distribution?

Answer: Most members were satisfied with the present methods but felt that only one procedure should be followed.

8. Question: Are you willing to follow the procedure preferred by a majority of the members or, if there is too much variation, some procedure to be worked out by the committee?

Answer: Nearly all members were willing to follow any reasonable procedure adopted by the committee.

During the spring of 1944 the committee studied the results of the questionnaire. In May 1944 the following plan was adopted:

I. The name will be changed to Duplicate Exchange Union. This will make it possible to send all types of duplicate lists, if a library desires to do so. It is requested that periodicals, books, documents, etc., be sent on separate lists.

2. Exchange lists should be sent simultaneously to all members and be filled in order of receipt. Some exceptions might be made where one library especially needs certain issues or volumes to complete a set.

3. The routing sheet will be discontinued and be replaced by a list of members which will be revised frequently. All libraries now in possession of a list and routing sheet are requested to return them to the original sender.

4. Each member may decide whether or not it wishes to send out want lists.

5. All members should make an attempt to send out at least two duplicate lists per year.

6. When a library wishes to discontinue its membership, it should notify all other members and the chairman of the committee.

7. The chairman of the committee will notify each library as new members are added to the union.

At the time the plan above was adopted a new routing sheet was compiled. This routing sheet now serves only as a list of members. Under the new procedure it is now possible to add new members at any time and libraries are continually requesting information about membership.

The membership of the Duplicate Exchange Union has remained almost constant until the fall of 1944 . In June 1940 there were sixty-four members. In the past two years only about five libraries have discontinued membership, their reasons being lack of personnel. To the writer's knowledge, no library has dropped membership because of dissatisfaction with the union, although some members have stated they do not obtain as many benefits as they would like. In October I 944 the membership of seventy-six was composed of forty-four college libraries, twenty-four university libraries, four public libraries, and four special libraries. New members are being constantly added.

It is believed that the union, on the whole, has been beneficial to its members. Some indicated that the value so far came only from being able to send out a great many duplicates that had stood on their shelves for a long time. However, the majority of the members feel, some very decidedly, that the Duplicate Exchange Union is filling a useful purpose. 